\title{
A terrestrial gamma-ray flash recorded at the Lightning Observatory in Gainesville, Florida
}

\author{
M.D. Tranª,*, V.A. Rakov ${ }^{\mathrm{a}}$, S. Mallick ${ }^{\mathrm{a}}$, J.R. Dwyer ${ }^{\mathrm{b}}$, A. Nag ${ }^{\mathrm{c}}$, and S. \\ Heckman $^{\text {d }}$ \\ ${ }^{a}$ Department of Electrical and Computer Engineering, University of Florida, \\ Gainesville, Florida, 32611, USA \\ ${ }^{b}$ Space Science Center (EOS), Department of Physics, University of New Hampshire, \\ Durham, New Hampshire, 03824, USA \\ ${ }^{c}$ Thunderstorm Systems and Data Division, Vaisala Inc., Louisville, Colorado, 80027, \\ $U S A$ \\ ${ }^{d}$ Earth Networks, 1240 Milestone Center Drive, Suite 300, Germantown, Maryland, \\ 20876, USA
}

\begin{abstract}
A terrestrial gamma-ray flash (TGF) observed at ground level is presented. It was recorded at the Lightning Observatory in Gainesville, Florida, on June 13, 2014. Ground-based observations of TGFs are very rare. To date, only two positively identified ones are found in the literature. Our TGF was associated with a single-stroke negative cloud-to-ground discharge. It had a duration of $16 \mu$ s and consisted of 6 pulses, two of which exceeded the upper measurement limit of $5.7 \mathrm{MeV}$. The pulses apparently corresponded to individual photons, which is a characteristic feature of TGFs. The TGF began $191 \mu$ s after the return-stroke electric field peak. The stepped leader duration was as short as $3.9 \mathrm{~ms}$. There was essentially no energetic radiation detected during the leader process. The NLDN-reported return-stroke peak current was as high as $224 \mathrm{kA}$. The characteristics and occurrence context of the LOG-recorded TGF are compared to those of the two similar events found in the literature. In all three cases there was evidence of a channel
\end{abstract}


carrying appreciable current to ground at the time of TGF, and the associated (preceding or concurrent) cloud-to-ground discharge processes were unusually intense.

Keywords:

lightning, energetic radiation, TGF

\section{Introduction and literature review}

Recent observations of hard x-rays and gamma-rays in thunderstorms (other than the enhancements of gamma-ray background due to precipitation of radon by rain) fall into three categories: surges in the gamma-ray background (gamma-ray glows) lasting seconds to minutes; bursts of x-rays associated with all kinds of natural and triggered lightning leaders, typically occurring within less than $1 \mathrm{~ms}$ of the return stroke; and Terrestrial Gamma-ray Flashes or TGFs (typically less than $1 \mathrm{~ms}$ in duration). The latter are usually observed from space, but on a few occasions were seen on the ground or from an aircraft. At present, the only viable mechanism for producing energetic radiation by lightning and thunderstorms involves runaway electrons, which occur when the energy gained by the free electrons between collisions, as they are accelerated by high electric field, exceeds the energy that is lost by collisions with air molecules. X-rays and gamma-rays are produced via what is called bremsstrahlung (braking radiation) that is emitted when a free electron is deflected in the electric field of a nucleus or, to a lesser extent, in the field of an atomic electron.

\footnotetext{
*Corresponding author

Email address: manhtran@ufl.edu (M.D. Tran) 
The energy spectrum of observed gamma-ray glows is consistent with the relativistic runaway electron avalanche (RREA) mechanism (also referred to as the relativistic runaway breakdown theory), which requires energetic (of the order of 0.1-1 MeV) seed electrons produced by cosmic rays and sufficiently high electric fields (calculated to be of the order of $100 \mathrm{kV} / \mathrm{m}$ at an altidue of $6 \mathrm{~km}$ ) extending over a sufficient distance (of the order of a kilometer). For all types of negative lightning leaders, the energy of individual x-ray photons was estimated to be in the 30 to $250 \mathrm{keV}$ range (the upper limit is twice the energy of a chest x-ray), although occasionally photons in the $\mathrm{MeV}$ range were observed. It is likely that x-ray emissions from cloudto-ground lightning leaders are associated with the so-called cold runaway (also known as thermal runaway) breakdown, in which very strong electric fields $(>30 \mathrm{MV} / \mathrm{m})$ cause the higher-energy tail of the bulk free electron population to grow, allowing some electrons to runaway to high energies. Such very high fields may be present at streamer heads or leader tips. It does not appear that runaway electron production is a necessary feature of lightning leaders. TGFs are associated with thunderstorms and individual lightning flashes, with accompanying electromagnetic signals (sferics) mostly suggesting intracloud flashes effectively transporting negative charge upward, including some compact intracloud discharges (CIDs), as the type of parent lightning.

All three TGFs reported from ground-based observations (including the one presented in this paper) occurred in Florida and were associated with cloud-to-ground discharges effectively transporting negative charge to ground. It is worth noting that we do not consider here x-ray/gamma-ray observations at ground level reported by Ringuette et al. (2013, 2014), be- 
cause some or all of their events (all labeled as TGFs) could be associated with leaders near ground, such events being outside the scope of this study. It is thought that TGFs are produced by in-cloud lightning processes, but it is not clear what the production mechanism is. One possibility is the cold runaway breakdown during the stepping process of a negative in-cloud leader. On the other hand, according to Dwyer and Cummer (2013), TGFs could be produced in the absence of ordinary lightning, via runaway breakdown processes alone. Since the latter processes emit little visible light, the phenomenon was referred to as dark lightning. Two TGF production mechanisms, RREAs in the large-scale homogeneous electric field inside the cloud and the acceleration of cold runaway electrons in the highly nonuniform electric field of in-cloud leader, are illustrated in Figure 1 of Xu et al. (2015). Additional information on energetic radiation from lightning is found in Dwyer et al. (2012b).

In this paper, we present the first TGF observed at the Lightning Observatory in Gainesville (LOG), Florida. It was identified using the following criteria: (a) no sign of pile-up, characteristic of x-rays associated with leaders near ground, is seen in the recorded pulses, (b) the duration of the recorded pulse sequence is less than $1 \mathrm{~ms}$, and (c) energy values for the largest pulses corresponding to individual photons, exceed $1 \mathrm{MeV}$. The characteristics and occurrence context of the LOG-recorded TGF are compared to those of the two similar events found in the literature. In order to make this comparison self-contained, we include a number of figures from the previous works. 


\section{Experimental setup}

The Lightning Observatory in Gainesville (LOG) was established on the University of Florida campus in 2004 primarily for measuring electromagnetic fields produced by lightning. An overview of recent results obtained at LOG is found in Rakov et al. (2014). Over the years the experimental setup has undergone upgrades, modifications, expansions, and relocation. It is currently located on the roof of the five-story New Engineering Building $\left(29^{\circ} 38^{\prime} 32^{\prime \prime} \mathrm{N} 82^{\circ} 20^{\prime} 50^{\prime \prime} \mathrm{W}\right)$. The LOG includes a glass cupola providing over a $180^{\circ}$ unobstructed view of the horizon. The cupola houses digitizing oscilloscopes, computers, and high-speed video cameras, with the various sensors and associated electronics being located nearby on the roof. The sensors currently include electric field antennas, electric field derivative $(\mathrm{d} E / \mathrm{d} t)$ antennas, magnetic field derivative $(\mathrm{d} B / \mathrm{d} t)$ antennas, and an x-ray detector. The low-gain and high-gain wideband electric field measuring systems have useful frequency bandwidths of $16 \mathrm{~Hz}$ to $10 \mathrm{MHz}$ and of $360 \mathrm{~Hz}$ to $10 \mathrm{MHz}$, respectively. The corresponding decay time constants are $10 \mathrm{~ms}$ and 440 $\mu$ s. The upper frequency bandwidth of the $\mathrm{d} E / \mathrm{d} t$ measurement system is $10 \mathrm{MHz}$. Signals from all the sensors are relayed by fiber-optic links to the glass cupola, where they are recorded and GPS-time stamped. A detailed description of LOG is given by Mallick et al. (2014b).

The TGF record presented here was obtained using the LOG x-ray detector that was previously used in the study of Mallick et al. (2012). The detector consisted of a 7.6-cm length and 7.6-cm diameter cylindrical NaI scintillator coupled with a photomultiplier tube and was powered by a $12-\mathrm{V}$ battery. A $0.32-\mathrm{cm}$ thick aluminum box shielded the detector from moisture and light, but allowed $\mathrm{x}$-rays with energies down to $30 \mathrm{keV}$ to enter from 
all direction. The output signal of the x-ray detector was transmitted via an analog fiber optic link, Opticomm FM, to an oscilloscope, sampling at $100 \mathrm{MHz}$.

We used a Cs-137 radioactive source (emitting $662 \mathrm{keV}$ photons) to calibrate the x-ray detector. The upper measurement limit was about $5.7 \mathrm{MeV}$ with the lowest measurable energy being $75 \mathrm{keV}$. The expected occurrence of background x-rays at LOG is 1 in 8 ms. Additional details about the $\mathrm{x}$-ray detector and background x-ray radiation at LOG can be found in Mallick et al. (2012, 2014a).

LOG data to be presented here include electric field and electric field derivative records corresponding to the observed gamma-ray emission. Unfortunately, no optical data are available for this event (it was outside of the fields of view of our high-speed video cameras installed at LOG).

We additionally used data from the US National Lightning Detection Network (NLDN), from the Earth Networks Total Lightning Network (ENTLN), and from the National Weather Service radar located near Jacksonville, FL, $112 \mathrm{~km}$ from the LOG.

\section{Data presentation}

On June 13, 2014, at about 15:53 (UT), a cell in a large (hundred kilometers in extent) thunderstorm system, moving from West to East, passed over Gainesville, Florida. Since its arrival until about 16:20 (UT), the thunderstorm cell, whose 18-dBZ echo top height was approximately $12 \mathrm{~km}$, produced numerous lightning discharges in the Gainesville area. During this time period, the maximum horizontal extent of the cell at an altitude of $5 \mathrm{~km}$ above ground increased from 14 to $28 \mathrm{~km}$. The TGF was asso- 
ciated with a negative single-stroke flash that occurred at 16:12:59 (UT) and terminated, according to the NLDN, at a distance of $7.5 \mathrm{~km}$ from the LOG. The NLDN also reported one pulse of the preliminary breakdown pulse train, which was located at a horizontal distance of $3 \mathrm{~km}$ from the return stroke, in the high-reflectivity ( $>45 \mathrm{dBZ}$ ) region of the cell, located at altitudes of 3-6 km above ground. The stroke to ground and PB pulse were detected by 20 and 3 NLDN sensors, respectively. It follows from the LOG electric field record that the return stroke was followed by a 20-ms duration continuing current. The negative return stroke was also reported by the ENTLN (detected by 527 sensors) and GLD360 (detected by 9 sensors), and the LF magnetic field sensor at Duke University at a distance of about $760 \mathrm{~km}$, but was missed by the World Wide Lightning Location Network (WWLLN). 


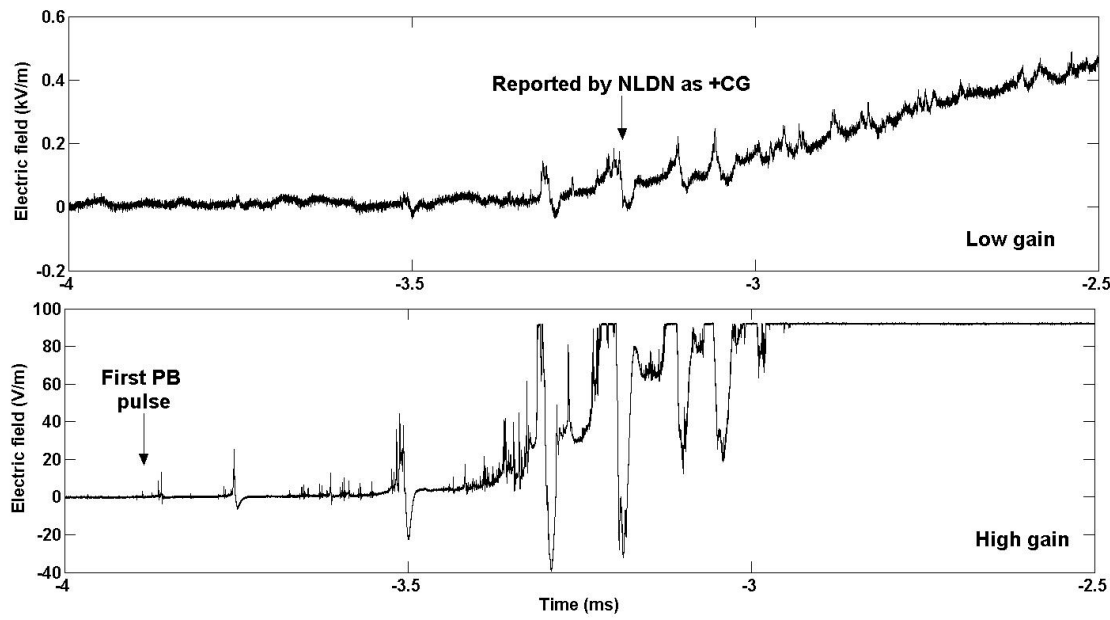

Figure 1: (top) low-gain and (bottom) high-gain electric field records of preliminary breakdown pulses of the TGF producing flash. One of the preliminary breakdown (PB) pulses, which was misclassified by the NLDN as a $50-\mathrm{kA}$ positive stroke $(+\mathrm{CG})$, is marked in the top panel. The first discernible electric field pulse in the high-gain field record that we attributed to $\mathrm{PB}$ occurred $3.9 \mathrm{~ms}$ prior to the return stroke.

The electric field of the beginning of the preliminary breakdown (PB) stage of the TGF-producing flash is shown in Figure 1. The first discernible PB pulse is marked in the lower panel in Figure 1, with no pulses exceeding twice the noise level being observed prior to that pulse. The first PB pulse preceded the return stroke by $3.9 \mathrm{~ms}$, which means that the stepped leader duration was very short. There are three possible explanations of that: the leader was very fast, or the main negative charge region was at unusually low altitude, or both. Zhu et al. (2014) found that such short-duration stepped leaders in Florida originated at normal altitudes and, hence, were unusually fast. The following return stroke currents in their study were very high, which is in line with the peak current $(224 \mathrm{kA})$ reported by the NLDN 
for our event. One of the preliminary breakdown pulses was misclassified by the NLDN as a 50-kA positive return stroke (+CG), located at a horizontal distance of $3 \mathrm{~km}$ from the negative-stroke ground termination point.
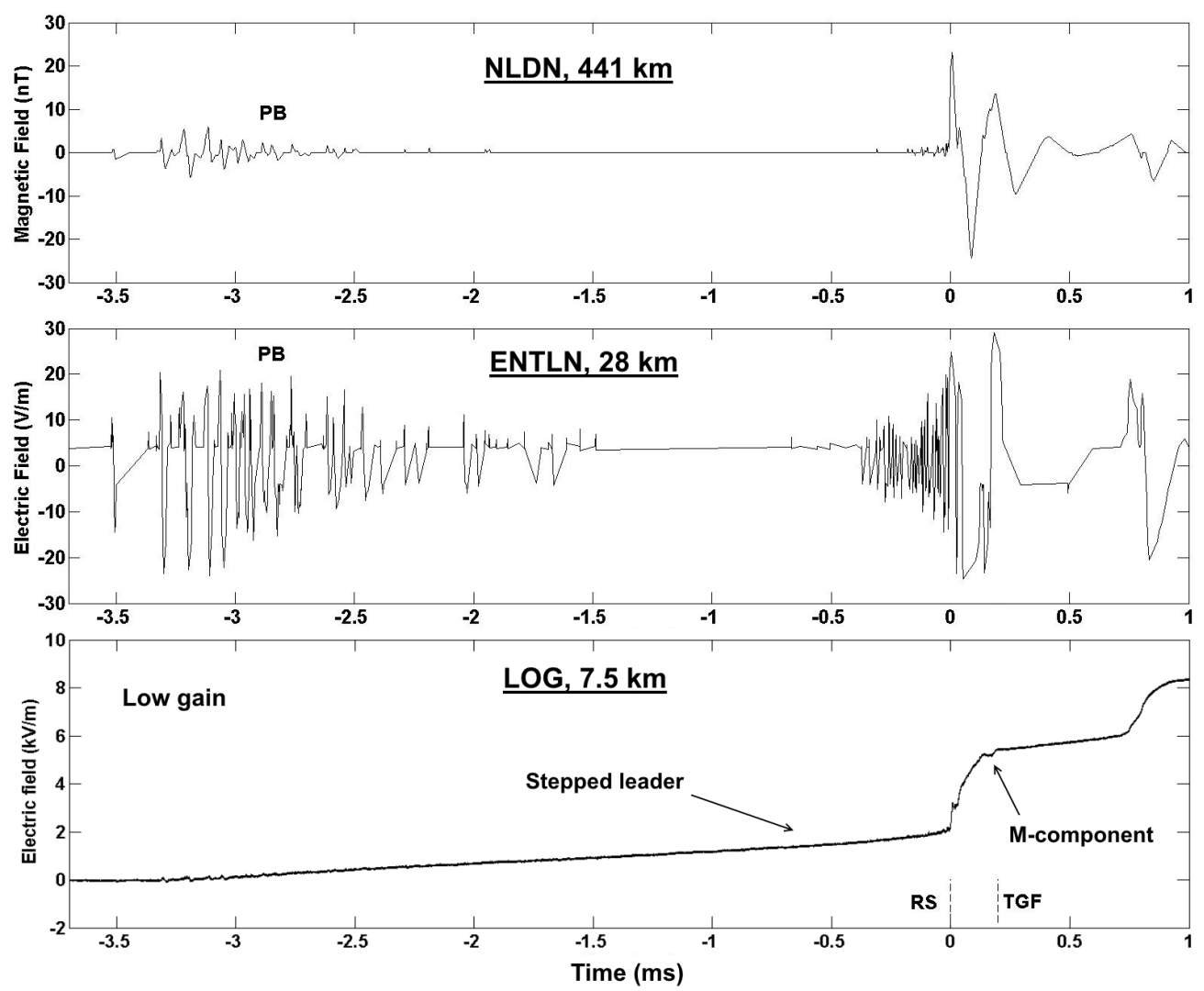

Figure 2: (top) Magnetic field at $441 \mathrm{~km}$, (middle) electric field at $28 \mathrm{~km}$, and (bottom) electric field at $7.5 \mathrm{~km}$ of TGF-producing stroke recorded by NLDN, ENTLN, and LOG, respectively. The linear vertical scale in the middle panel applies only to the $\pm 15 \mathrm{~V} / \mathrm{m}$ range (the sensor response is non-linear outside that range). The LOG waveform in the bottom panel is compensated to remove the 10-ms instrumental decay. PB and RS stand for preliminary breakdown and return stroke, respectively. Vertical broken lines (separated by $191 \mu \mathrm{s}$ ) in the bottom panel indicate the times of RS initial peak and TGF first pulse. 

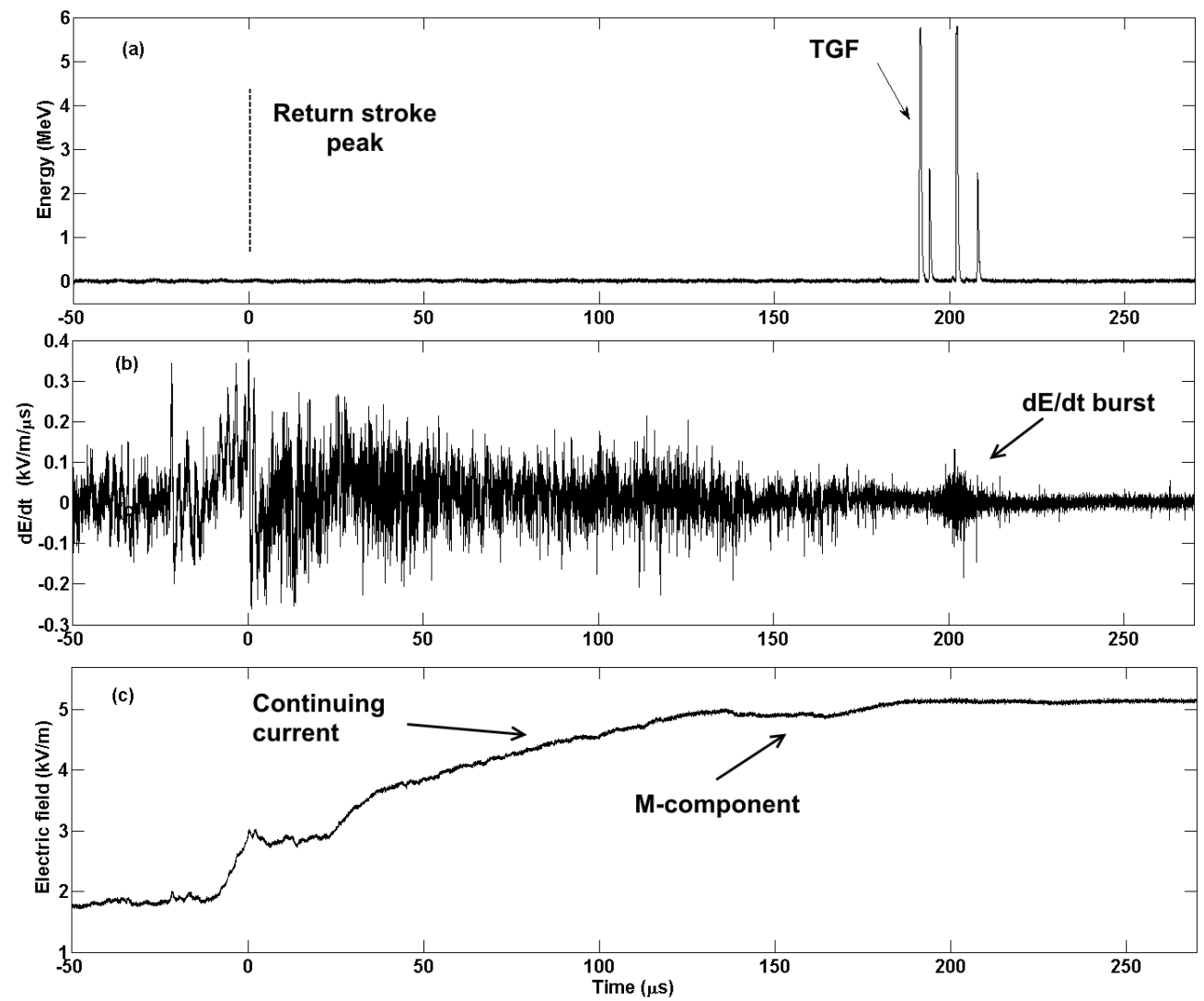

Figure 3: (a) TGF observed at LOG on June 13, 2014. It had a duration of $16 \mu \mathrm{s}(6$ x-ray/gamma-ray pulses, 2 of which can only be seen on an expanded vertical scale), and began $191 \mu \mathrm{s}$ after the return-stroke electric field peak. (b) $\mathrm{d} E / \mathrm{d} t$ and (c) lowgain electric field records acquired at LOG $(7.5 \mathrm{~km}$ from the channel to ground). The NLDN-reported return-stroke peak current was $224 \mathrm{kA}$.

The magnetic field at $441 \mathrm{~km}$ and electric field at $28 \mathrm{~km}$ of the TGFproducing stroke recorded by the NLDN and ENTLN, respectively are presented, as examples, in Figure 2. Also shown in Figure 2 is the low-gain electric field record obtained at LOG. Not counting the LOG waveforms, the ENTLN waveform is the closest of all the available waveforms for this event. It shows the preliminary breakdown pulse train (about $2 \mathrm{~ms}$ in du- 
ration), a quiet interval (about $1 \mathrm{~ms}$ in duration), leader pulses (between $-0.5 \mathrm{~ms}$ and 0 ), and return stroke (RS) waveform (whose initial peak is at $t=0$ ). During the leader stage, only one $930 \mathrm{keV}$ x-ray/gamma-ray pulse was detected $1.34 \mathrm{~ms}$ before the return-stroke electric field peak. The TGF began $191 \mu$ s after the return-stroke initial field peak (see vertical broken lines in the bottom panel of Figure 2).
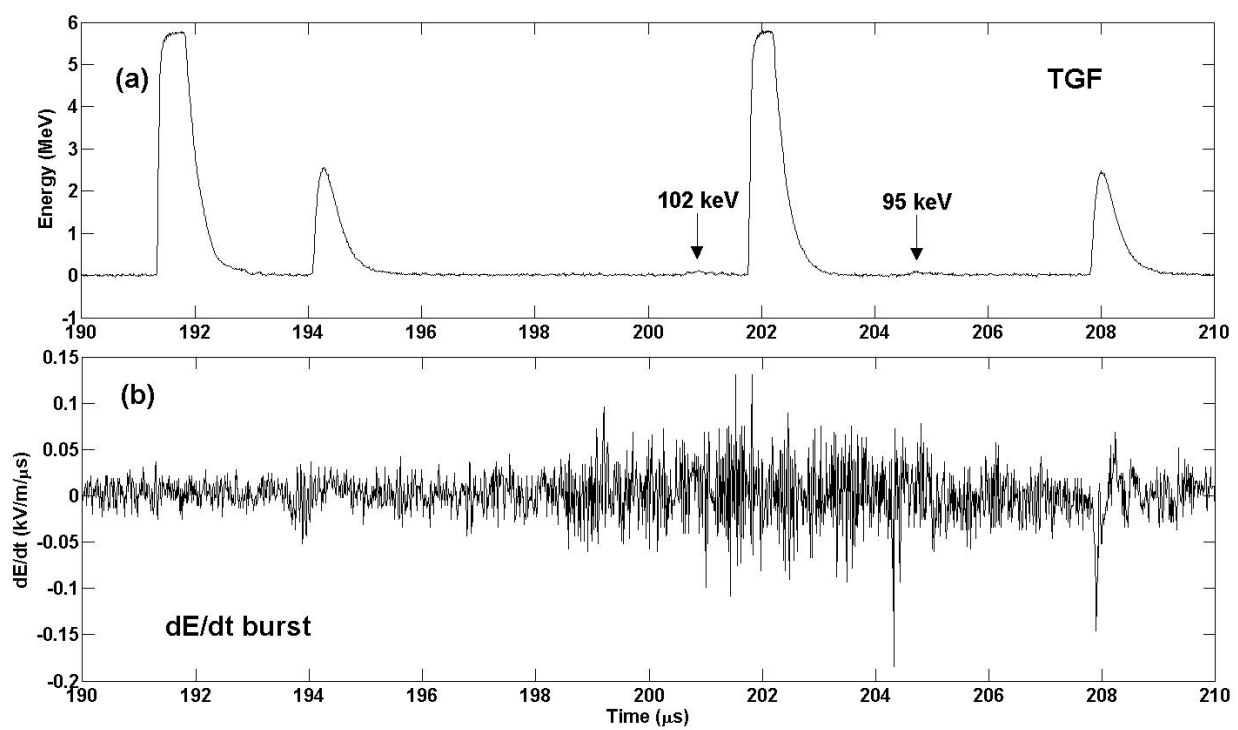

Figure 4: (a) Six TGF pulses and (b) corresponding $\mathrm{d} E / \mathrm{d} t$ waveform, recorded at LOG and shown on a $20-\mu$ s time scale. Two smallest pulses in (a) are marked with their energies. Magnitudes of the two saturated pulses were estimated, via reconstruction described by Dwyer et al. (2012a), to be 13 and $10 \mathrm{MeV}$. Note $\mathrm{d} E / \mathrm{d} t$ burst (better seen in Figure 3b) peaking near $202 \mu \mathrm{s}$.

Figure 3 shows, from top to bottom, x-ray/gamma-ray, $\mathrm{d} E / \mathrm{d} t$, and electric field records of the TGF-producing stroke, respectively, all obtained at LOG. The 16- $\mu$ s-long TGF started $191 \mu$ s after the return-stroke electric field peak (202 $\mu$ s after the return-stroke onset). The TGF consists of six 
pulses, two of which are clipped at $5.7 \mathrm{MeV}$. Of the other four, two are slightly larger than $2 \mathrm{MeV}$, and two have energies of 102 and $95 \mathrm{keV}$. Since no sign of pile-up was found in the 6 TGF pulses seen in Figure 4a (although the 2 smallest pules are significantly influenced by noise), they were assumed to be produced by 6 individual photons. Due to the background noise, we are not sure whether the two other pulses were produced by single photons. The expected background x-ray/gamma-ray occurrence at LOG is about 1 pulse per 8 ms (Mallick et al., 2012). The probability of occurrence of 6 background x-ray pulses in $16 \mu$ s, assumed to obey Poisson probability distribution, is $8.9 \times 10^{-20}$. Thus, we can essentially rule out the possibility that the background x-ray/gamma-ray radiation was the source of the observed signature. Interestingly, the TGF was apparently accompanied by a $\mathrm{d} E / \mathrm{d} t$ burst seen in Figures $3 \mathrm{~b}$ and $4 \mathrm{~b}$. This feature has never been reported before.

As noted above, the LOG electric field record suggests that the return stroke was followed by a continuing current. Its initial part appears as a ramp-like field change in Figures 2c and 3c. A shallow hook-shaped electric field change starting during the ramp-like field change can be seen in Figure 3c between 130 and $190 \mu \mathrm{s}$, which is likely to be produced by an Mcomponent. Visacro et al. (2013), who examined M-component currents following first strokes in natural lightning measured at an instrumented tower, reported that the elapsed time between the return stroke peak and the beginning of M-component in natural lightning ranged from 0.09 to $2 \mathrm{~ms}$. The time interval between the return stroke and the hook-shaped electric field change in Figures $2 \mathrm{c}$ and $3 \mathrm{c}$ is consistent with that range of elapsed times. The duration (about $60 \mu \mathrm{s}$ ) of the hook-shaped field change in Figure 3c is 
considerably smaller than typical values (hundreds of microseconds) found in the literature (Malan and Schonland, 1947; Thottappillil et al., 1995). Visacro et al. (2013) also found that the first-stroke M-components are more intense and transfer to ground 3 times more charge than those following subsequent strokes in rocket-triggered lightning (Thottappillil et al., 1995).

\section{Comparison with previous observations and discussion}

As of this writing, only two positively identified TGFs observed at ground level are found in the literature. The first one, associated with a negative rocket-triggered lightning flash at Camp Blanding, Florida, was observed on August 15, 2003. The second one occurred after the negative return stroke of a natural CG flash at the same research facility on June 30, 2009. The TGF record of the former is presented in Figure 5, in which the six panels are six consecutive $75-\mu$ s segments of a $450-\mu$ s portion of the x-ray/gamma-ray record. A total of 227 pulses corresponding for 227 individual photons were detected within $300 \mu$ s. Figure 6 shows the channel-base current of the flash. The gamma-ray burst coincided with an ICC pulse shown on an expanded (2-ms) time scale, along with the TGF, in Figure 7. The second TGF-producing flash found in the literature contained a single stroke, whose NLDN-reported peak current was as high as $99 \mathrm{kA}$. The x-ray/gamma-ray, optical intensity, and close vertical electric field records of this event are presented in Figure 8. The TGF was $53-\mu \mathrm{s}$ in duration and started $191 \mu$ s after the return stroke onset.

Characteristics of the $3 \mathrm{TGF}$ events (including the one recorded at LOG) are summarized in Table 1 . The TGFs associated with the two natural 13 
flashes both occurred in unusually intense single-stroke flashes (in particular our event), about $200 \mu$ s after the return stroke. The TGF associated with the triggered flash occurred during an unusual large (11-kA) ICC pulse. 


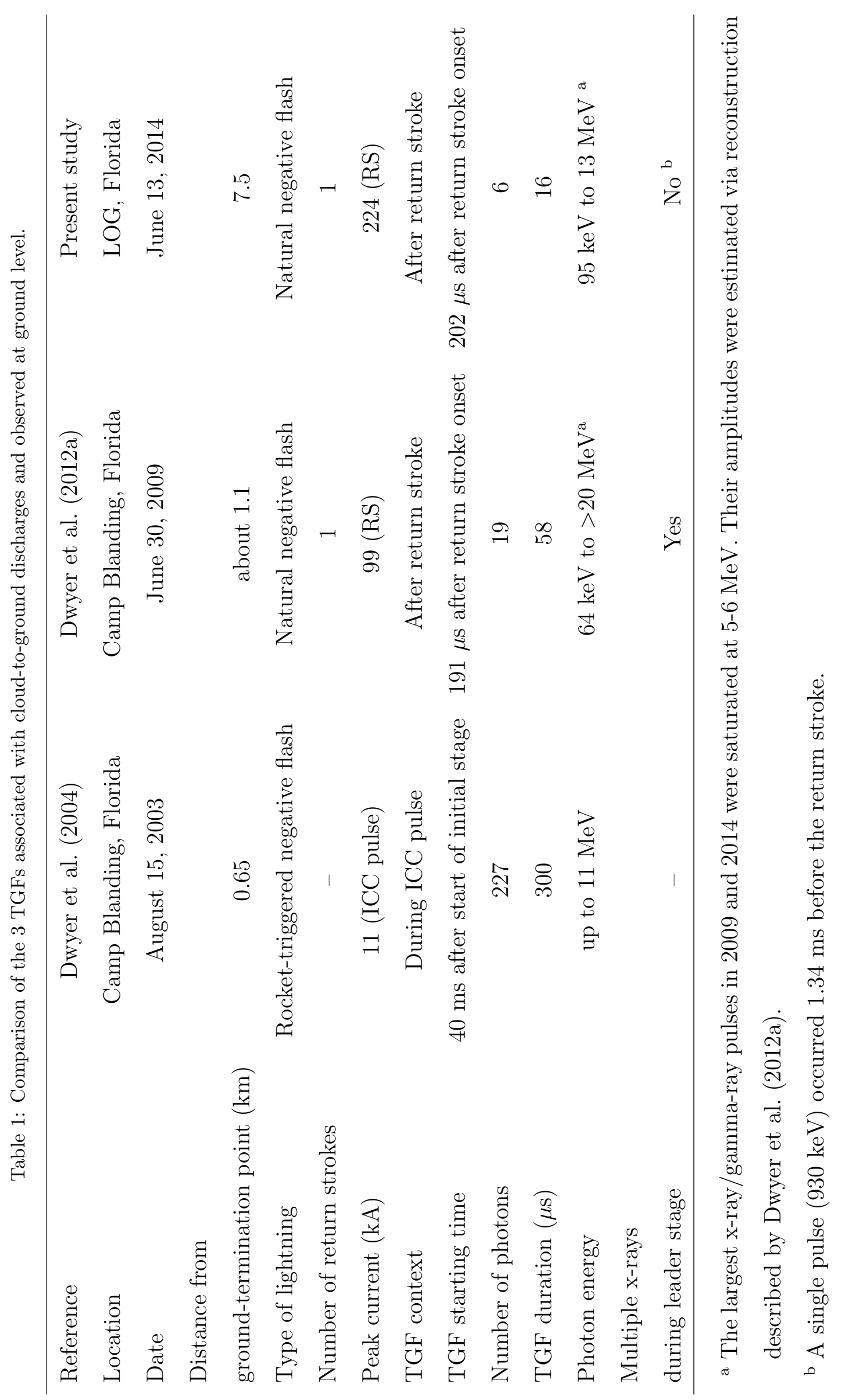




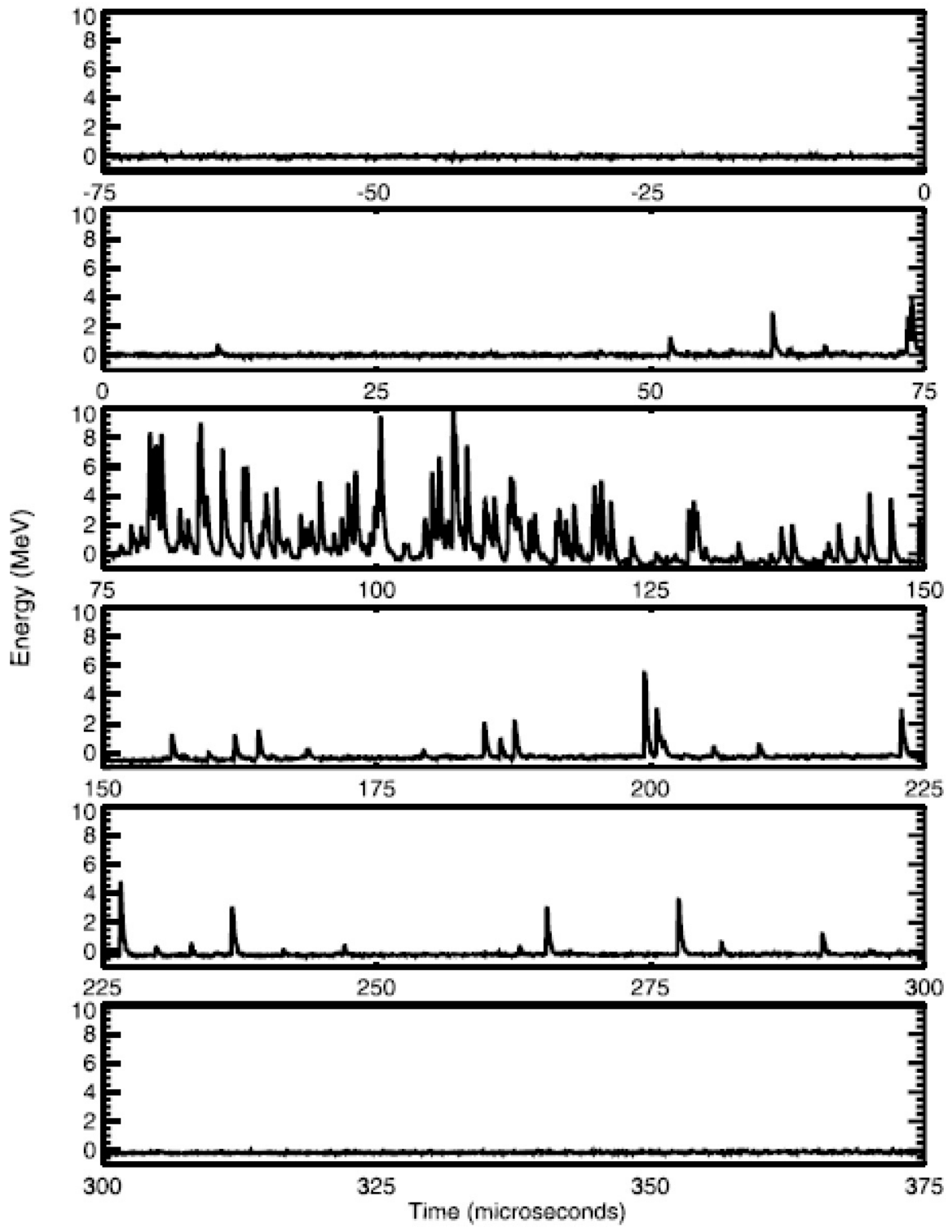

Figure 5: Gamma-ray burst associated with a rocket-triggered lightning flash at Camp Blanding, Florida, on August 15, 2003. Each pulse is produced by the detection of an individual gamma-ray (a total of 227 over a $300-\mu$ s time interval). The raw data have been multiplied by $-36 \mathrm{MeV} / \mathrm{V}$, so that the energy of the individual gamma-rays can be read. The six panels show the consecutive $75 \mu$ s segments of the $450 \mu$ s portion of the record. Adapted from Dwyer et al. (2004). 


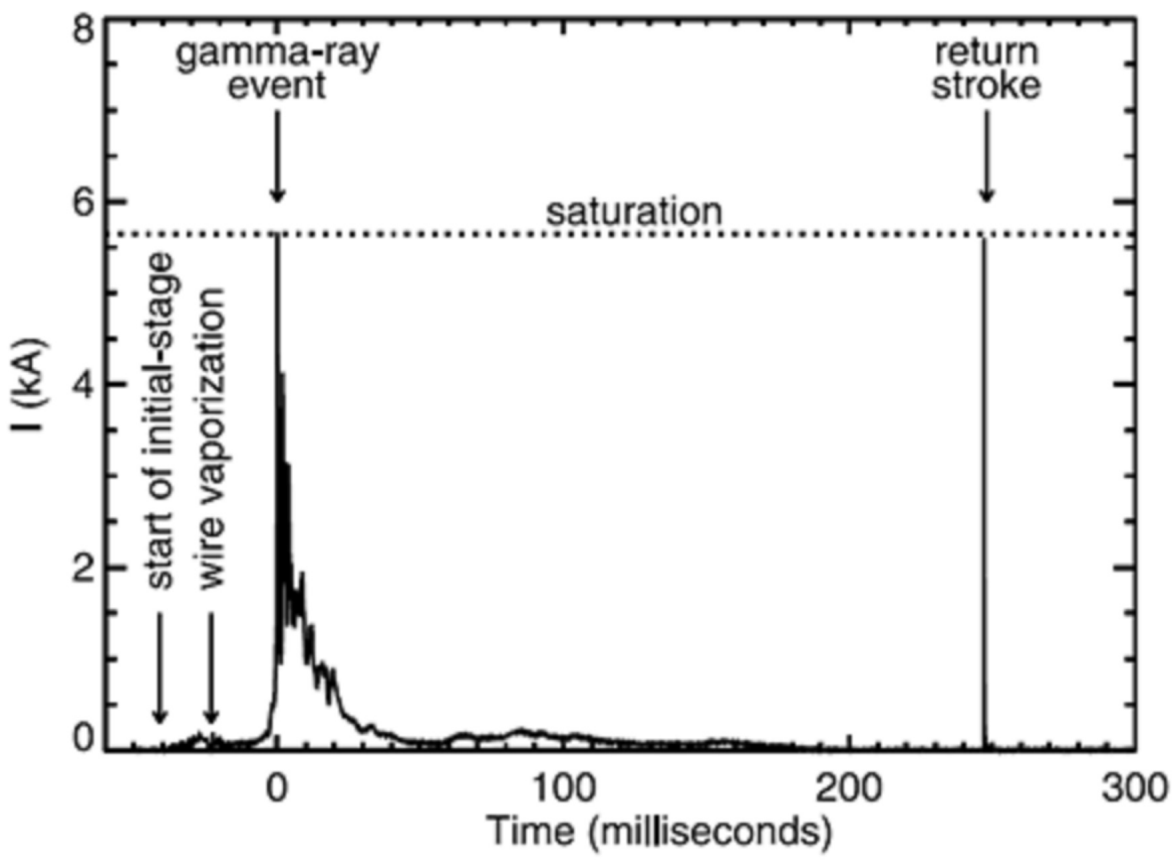

Figure 6: Electric current, measured at the rocket launcher, for the lightning triggered on 15 August 2003. The arrows indicate the start of the initial-stage, which corresponds to the beginning of the upward propagating positive leader; the time of the ICV associated with the wire vaporization; the time of the observed gamma-ray burst and the time of the return stroke. During the initial-stage, a total of $57 \mathrm{C}$ was brought to the ground, which is about a factor of two greater than typical values for triggered lightning. Adapted from Dwyer et al. (2004). 


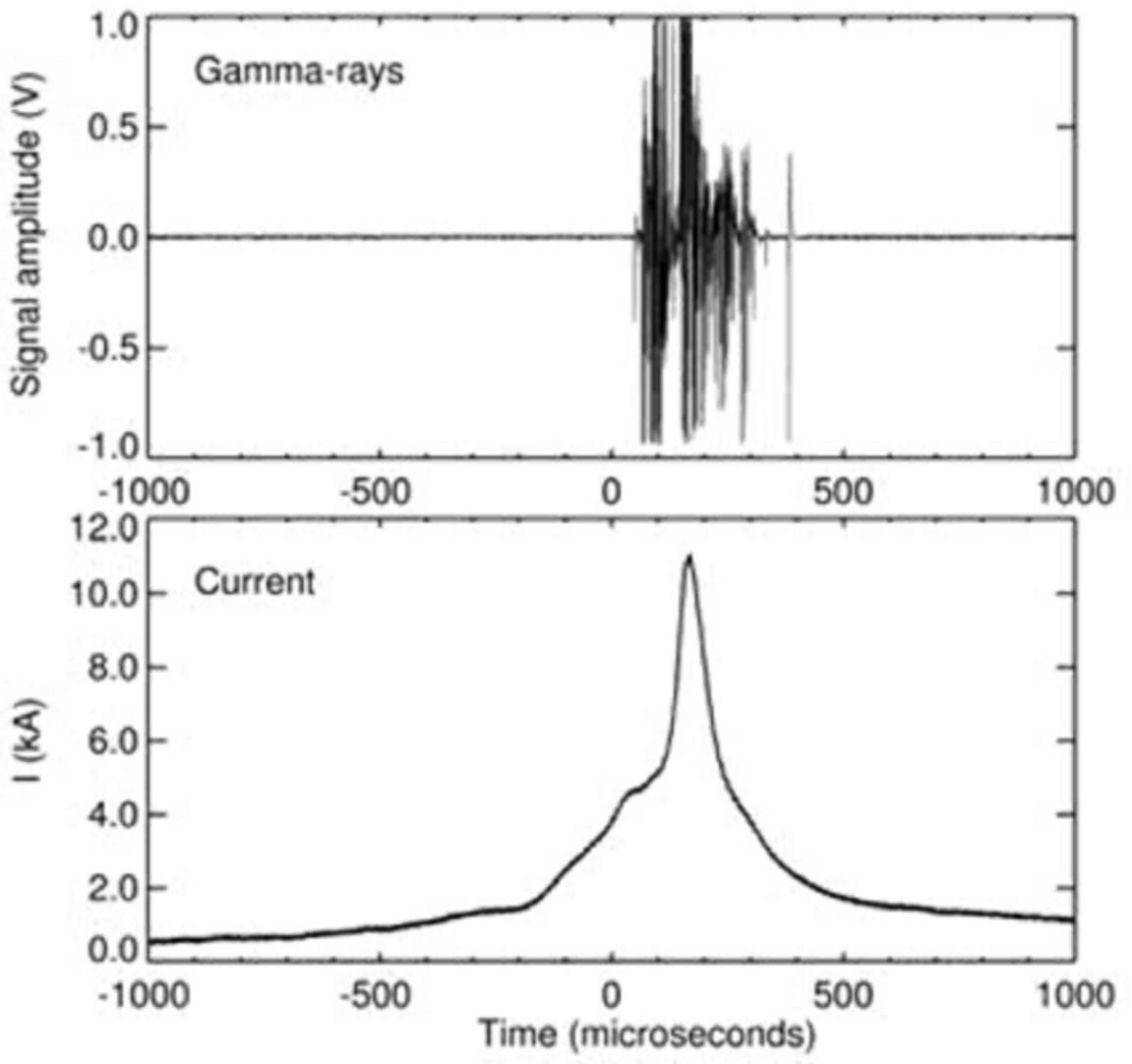

Figure 7: Expanded view of the time period shown in Figure 6. The top panel shows the gamma-ray data as measured by the $12.7-\mathrm{cm} \mathrm{NaI}$ detector in the first instrument. The bottom panel shows the electric current data, measured at the lightning channel base. The TGF began when the channel-base current was about $4.5 \mathrm{kA}$. Adapted from Dwyer et al. (2004). 

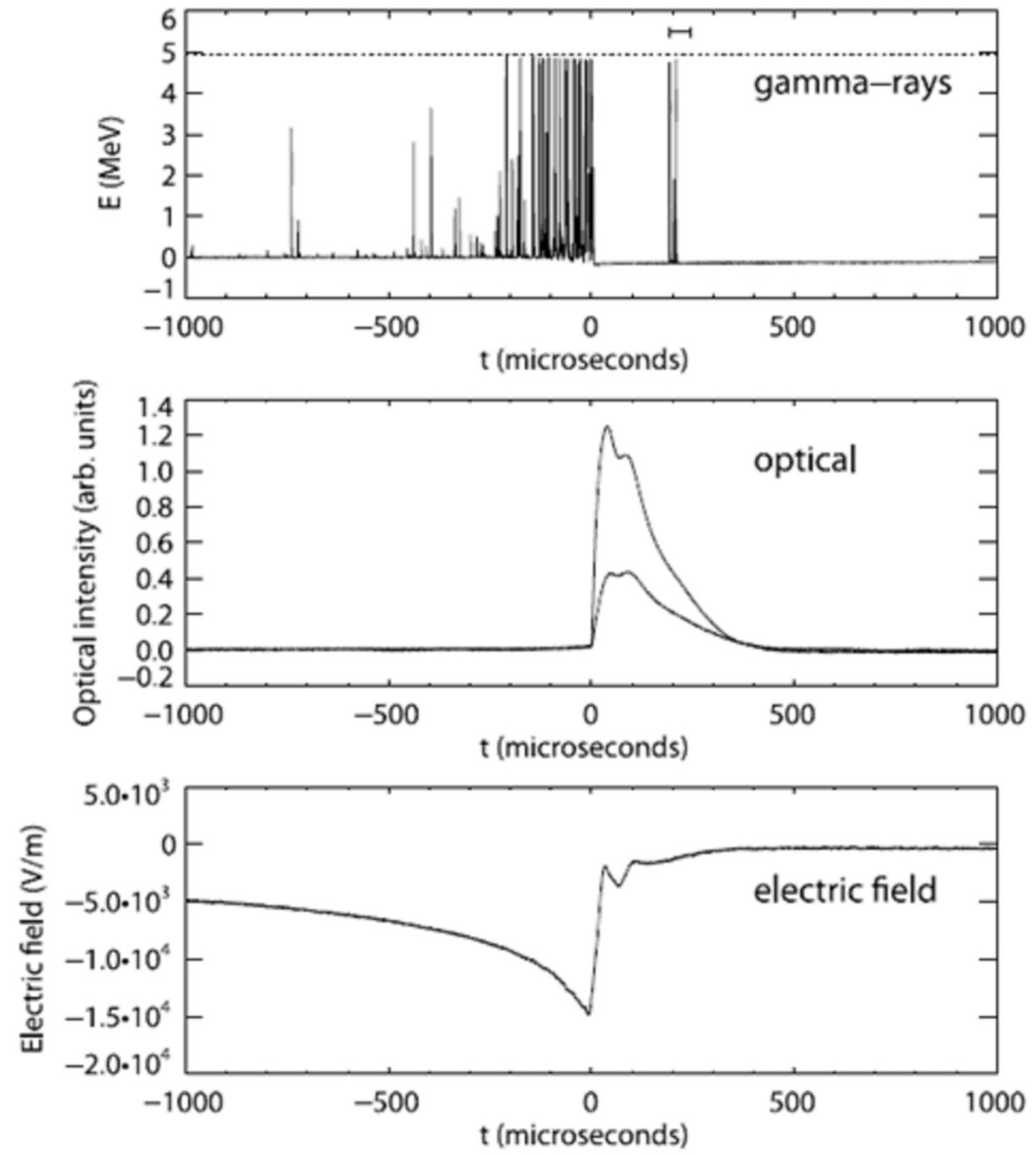

Figure 8: (top) x-ray and gamma-ray emissions measured from the June 30, 2009 natural CG lightning at Camp Blanding, Florida. The start of the return stroke is at $t=0$. The emissions before the return stroke are x-rays from the stepped leader. The $53-\mu \mathrm{s}$ burst (19 pulses) starting at $191 \mu \mathrm{s}$ is the gamma-ray flash. The horizontal dotted line shows where the signals are clipped due to saturation of the fiber optic electronics. The small horizontal bar shows the duration of the gamma-ray flash on all detectors. (middle) Optical emission from the return stroke measured by two detectors facing southwest and northeast (the larger signal). (bottom) Vertical electric field measured at station E-10 at a distance of $800 \mathrm{~m}$, according to the NLDN. The negative deflection is due to the stepped leader lowering negative charge to the ground. NLDN-reported peak current was 99 kA. Adapted from Dwyer et al. (2012a). 
We presented here a third positively identified TGF observed at ground level (the first one at LOG). Each additional ground-based recording of TGF is very valuable, since they are very rare. TGFs are produced by still not well understood in-cloud processes, as opposed to x-ray signatures associated with leaders near ground. Dwyer and Cummer (2013), based on the theory of relativistic feedback discharge ("dark lightning"), predicted characteristic VLF/LF field waveforms with 200- $\mu$ s zero-crossing time for TGF events. For our TGF event, we recorded at LOG only a close electric field waveform, which is dominated at the time of TGF occurrence by the electrostatic field component. Distant field waveforms recorded by the ENTLN and NLDN show a large pulse that begins prior to the TGF onset. Examples from the NLDN and ENTLN are shown in the top and middle panels in Figure 2, respectively. The ENTLN waveform was recorded with an analog bandwidth of $5 \mathrm{kHz}$ to $10 \mathrm{MHz}$, digitized with a sampling interval of $42 \mathrm{~ns}$, and then compressed. The NLDN waveform was recorded with a bandwidth of $400 \mathrm{~Hz}$ to $400 \mathrm{kHz}$ and was sampled every $200 \mathrm{~ns}$. It was also compressed.

Mallick et al. (2012) recorded 23 strokes (8 first and 15 subsequent) within $2 \mathrm{~km}$ of the LOG. Out of the 23 strokes, 14 produced single x-ray pulses or x-ray bursts (sequences of two or more pulses), and 9 did not produce detectable x-ray emissions. Not all strokes within the same flash produced x-rays, and 5 out of 7 subsequent-stroke (dart or dart-stepped) leaders produced more $\mathrm{x}$-ray pulses than their corresponding first-stroke leaders. In one flash, all three strokes recorded at LOG produced x-rays, but the third stroke was much more prolific x-ray producer (a total of 109 discernible pulses) than the other two strokes (19 and 3 pulses). It is important to note that some pulses were due to multiple photons arriving 
within the response time (about $1 \mu \mathrm{s}$ ) of the x-ray detector; that is, were actually each a superposition (pile-up) of two or more individual pulses. All discernible individual pulses were included in the pulse count given above. All three strokes occurred in the same channel. For the third stroke, some pulses associated with individual photons were in excess of $2 \mathrm{MeV}$ and in one case greater than $5 \mathrm{MeV}$. In fact, the x-ray burst of this stroke was unusually intense and could be viewed as TGF if not the piling-up effect (photons arriving in sub-microsecond bursts, which is characteristic of x-ray emissions of leaders near ground). NLDN-reported peak currents for strokes 1 and 3 were similar (50 and $55 \mathrm{kA}$, respectively). Nevertheless, the number of x-ray pulses produced by strokes 1 and 3 differed dramatically. One possible explanation of this observation is beaming of the source electrons (different for different steps or segments of the leader channel). However, Saleh et al. (2009) found, for triggered-lightning leaders, that the source electrons are probably emitted isotropically. According to a more recent study (Schaal et al., 2013), the emission may be not isotropic for individual leader steps, but is isotropic for all steps combined. Another explanation of the lack of x-rays from some steps, offered by Mallick et al. (2012), is that the electric field enhancements $(>30 \mathrm{MV} / \mathrm{m}$ or so for the case of normal air density), needed for the cold runaway breakdown, are very brief and highly localized, so that in many cases an electron capable of starting the efficient x-ray-producing runaway process may be unavailable. On the other hand, it is often assumed (e.g., Moss et al., 2006) that any low-energy free electron in the presence of external electric field greater than about $262 \mathrm{kV} / \mathrm{cm}$ (at ground-level air density) will run away and generate x-rays, but they may be not energetic enough to be detectable. Overall, it seems that the cold 
runaway breakdown may be not a necessary feature of lightning leaders, although this fundamental question remains unanswered.

Cooray et al. $(2009,2010)$ have advanced a theory of how dart leaders might produce $\mathrm{x}$-rays. It relies on the cold electron runaway mechanism which operates in previously conditioned lightning channels when the dart leader electric field briefly exceeds (by a factor of 10 or so) the conventional breakdown value. Mallick et al.'s (2012) observation that subsequent-stroke leaders were often more prolific producers of detectable x-rays than their corresponding first-stroke leaders is in support of the theory of Cooray et al. (2009, 2010). According to that theory, a low-density channel traversed by subsequent-stroke leaders is more conducive to occurrence of the cold runaway breakdown than the virgin air in which first-stroke leaders have to develop. This finding may have implications for production of TGFs, which may also preferentially occur via secondary breakdown retracing the remnants of a previously conditioned channel or a cloud region. Specifically, the following hypothetical scenario can be inferred from the contexts in which the newly-observed TGF and two previously published ones have occurred. In all three cases there was evidence of a channel carrying appreciable current to ground. It is likely that this current was supplied by a branched positive in-cloud leader. Individual branches of the leader could be at different stages of development, some actively growing while others decaying. It is known that, in the presence of an active channel to ground, decayed branches can facilitate the occurrence of M-componenttype transients. Such transients are often initiated by so-called recoil leaders whose negative ends develop in decayed positive leader branches toward the current-carrying channel to ground. Conditions for cold runaway break- 
down and resultant gamma-ray emission could be created by the warm, low density medium (decayed in-cloud branch channel) and super-fields briefly produced in the tip of recoil leader. This scenario is admittedly speculative and does not explain the occurrence of our TGF after the M-component onset. Other scenarios are possible. For example, Dwyer et al. (2012a) suggested that their TGF could have come from the defunct negative leader branches that were quickly brought to nearly ground potential during the return stroke, thus causing the electric fields in their streamer zones to reverse and reach large magnitudes. These electric fields near the leader branch tips may cause RREA multiplication, augmented by either cold runaway electron emission or relativistic feedback, capable of TGF generation. In applying this scenario of recharging leader branches during the return stroke to our case, it is not clear why those same branches did not produce x-ray emissions during the leader stage. Clearly, further research (including observations from orbit, in mid air, and at ground, as well as associated modeling) is needed to improve our understanding of the nature of TGFs and their sources.

\section{Summary}

We presented a third positively identified TGF recorded at ground level. One of the previously reported TGFs occurred during the initial stage of a rocket-triggered negative flash and the other was observed about $191 \mu$ s after the return-stroke onset of a natural negative single-stroke flash. Our TGF, recorded at LOG, Florida, was detected $202 \mu$ s after the onset of the only return stroke in a natural negative lightning flash and was accompanied by a $\mathrm{d} E / \mathrm{d} t$ burst. The stepped-leader duration was as short as $3.9 \mathrm{~ms}$. 
During the leader stage, essentially no energetic radiation was detected, in contrast with the previously reported TGF-producing natural flash. The NLDN-reported peak current of the return stroke was $224 \mathrm{kA}$. The newlyobserved TGF and previously reported ones occurred in similar contexts. In all three cases there was evidence of a channel carrying appreciable current to ground. The TGFs associated with the two natural flashes both occurred in unusually intense single-stroke flashes (in particular our event), about $200 \mu$ s after the return stroke. The TGF associated with the triggered flash occurred during an unusual large (11-kA) ICC pulse.

\section{Acknowledgments}

This work was supported in part by NSF and DARPA. Useful discussions with Drs. Robert H. Holzworth and Steven A. Cummer are acknowledged.

\section{Refrences}

Cooray, V., Becerra, M., Rakov, V. A., 2009. On the electric field at the tip of dart leaders in lightning flashes. Journal of Atmospheric and Solar-Terrestrial Physics 71 (12), 1397 -1404 .

URL http://www.sciencedirect.com/science/article/pii/S1364682609001497

Cooray, V., Dwyer, J. R., Rakov, V. A., Rahman, M., 2010. On the mechanism of x-ray production by dart leaders of lightning flashes. Journal of Atmospheric and SolarTerrestrial Physics 72 (1112), $848-855$.

URL http://www.sciencedirect.com/science/article/pii/S1364682610001227

Dwyer, J. R., Cummer, S. A., 2013. Radio emissions from terrestrial gamma-ray flashes. Journal of Geophysical Research: Space Physics 118 (6), 3769-3790.

URL http://dx.doi.org/10.1002/jgra.50188

Dwyer, J. R., Rassoul, H. K., Al-Dayeh, M., Caraway, L., Wright, B., Chrest, A., Uman, M. A., Rakov, V. A., Rambo, K. J., Jordan, D. M., Jerauld, J., Smyth, C., 2004. A 24 
ground level gamma-ray burst observed in association with rocket-triggered lightning. Geophysical Research Letters 31 (5).

URL http://dx.doi.org/10.1029/2003GL018771

Dwyer, J. R., Schaal, M. M., Cramer, E., Arabshahi, S., Liu, N., Rassoul, H. K., Hill, J. D., Jordan, D. M., Uman, M. A., 2012a. Observation of a gamma-ray flash at ground level in association with a cloud-to-ground lightning return stroke. Journal of Geophysical Research: Space Physics 117 (A10).

URL http://dx.doi.org/10.1029/2012JA017810

Dwyer, J. R., Smith, D. M., Cummer, S. A., 2012b. High-energy atmospheric physics: Terrestrial gamma-ray flashes and related phenomena. Space Science Reviews 173 (14), 133-196.

URL http://dx.doi.org/10.1007/s11214-012-9894-0

Malan, D. J., Schonland, B. F. J., 1947. Progressive Lightning, 7, Directly Correlated Photographic and Electrical Studies of Lightning from near Thunderstorms. Proc. R. Soc. London Ser. A. 191, 485-503.

Mallick, S., Rakov, V. A., Dwyer, J. R., 2012. A study of x-ray emissions from thunderstorms with emphasis on subsequent strokes in natural lightning. Journal of Geophysical Research: Atmospheres 117 (D16).

URL http://dx.doi.org/10.1029/2012JD017555

Mallick, S., Rakov, V. A., Dwyer, J. R., June 2014a. X-ray emissions from first and subsequent leaders in natural cloud-to-ground lightning. In: XV International Conference on Atmospheric Electricity. Oral presentation O-06-01.

URL http://www.nssl.noaa.gov/users/mansell/icae2014/preprints/Mallick_167.pdf

Mallick, S., Rakov, V. A., Tsalikis, D., Nag, A., Biagi, C. J., Hill, D., Jordan, D. M., Uman, M. A., Cramer, J. A., 2014b. On remote measurements of lightning return stroke peak currents. Atmospheric Research 135 - 136, $306-313$.

URL http://www.sciencedirect.com/science/article/pii/S016980951200275X

Moss, G. D., Pasko, V. P., Liu, N., Veronis, G., 2006. Monte carlo model for analysis of thermal runaway electrons in streamer tips in transient luminous events and streamer zones of lightning leaders. Journal of Geophysical Research: Space Physics 111 (A2), A02307. 
URL http://dx.doi.org/10.1029/2005JA011350

Rakov, V. A., Mallick, S., Nag, A., Somu, V. B., Mar. 2014. Lightning Observatory in Gainesville (LOG), Florida: A review of recent results. Electric Power Systems Research.

URL http://linkinghub.elsevier.com/retrieve/pii/S0378779614000893

Ringuette, R., Case, G. L., Cherry, M. L., Granger, D., Guzik, T. G., Stewart, M., Wefel, J. P., 2013. Tetra observation of gamma-rays at ground level associated with nearby thunderstorms. Journal of Geophysical Research: Space Physics 118 (12), 7841-7849. URL http://dx.doi.org/10.1002/2013JA019112

Ringuette, R., Cherry, M. L., Granger, D., Guzik, T. G., Stewart, M., Wefel, J. P., June 2014. Gamma rays associated with nearby thunderstorms at ground level. In: XV International Conference on Atmospheric Electricity. Oral presentation O0602. URL http://www.nssl.noaa.gov/users/mansell/icae2014/preprints/Ringuette_234.pdf

Saleh, Z., Dwyer, J. R., Howard, J., Uman, M. A., Bakhtiari, M., Concha, D., Stapleton, M., Hill, D., Biagi, C. J., Rassoul, H., 2009. Properties of the x-ray emission from rocket-triggered lightning as measured by the thunderstorm energetic radiation array (tera). Journal of Geophysical Research: Atmospheres 114 (D17).

URL http://dx.doi.org/10.1029/2008JD011618

Schaal, M. M., Dwyer, J. R., Rassoul, H. K., Hill, J. D., Jordan, D. M., Uman, M. A., 2013. The angular distribution of energetic electron and x-ray emissions from triggered lightning leaders. Journal of Geophysical Research: Atmospheres 118 (20), 11,71211,726 .

URL http://dx.doi.org/10.1002/2013JD019619

Thottappillil, R., Goldberg, J. D., Rakov, V. A., Uman, M. A., Fisher, R. J., Schnetzer, G. H., 1995. Properties of M components from currents measured at triggered lightning channel base. Journal of Geophysical Research: Atmospheres 100 (D12), 25711-25720. URL http://dx.doi.org/10.1029/95JD02734

Visacro, S., Araujo, L., Guimares, M., Vale, M. H. M., 2013. M-component currents of first return strokes in natural negative cloud-to-ground lightning. Journal of Geophysical Research: Atmospheres 118 (21), 12,132-12,138, 2013JD020026.

URL http://dx.doi.org/10.1002/2013JD020026 
Xu, W., Celestin, S., Pasko, V. P., 2015. Optical emissions associated with terrestrial gamma ray flashes. Journal of Geophysical Research: Space Physics 120 (2), 13551370, 2014JA020425.

URL http://dx.doi.org/10.1002/2014JA020425

Zhu, Y., Rakov, V. A., Mallick, S., Tran, D. M., June 2014. Preliminary breakdown pulse trains in electric field records of negative cloud-to-ground lightning. In: XV International Conference on Atmospheric Electricity. Poster presentation P0314.

URL http://www.nssl.noaa.gov/users/mansell/icae2014/preprints/Zhu_323.pdf 